\title{
Oswald revisited: the effect of focus and context
}

\author{
Eugenia Kulakova ${ }^{1}$ (1) $\cdot$ Stefan Rinner $^{2}$ (])
}

Received: 29 January 2021 / Accepted: 27 October 2021 / Published online: 22 February 2022

(C) The Author(s) 2022, corrected publication 2022

\begin{abstract}
In this paper, we will present an analysis of the Oswald example ('If Oswald did not shot Kennedy, then somebody else did'/'If Oswald had not shot Kennedy, then somebody else would have') that takes a closer look at the antecedents of the Oswald minimal pair. We will argue that diverging foci in the antecedents of the Oswald example result in different truth conditions of the conditionals, explaining the difference in truth values between the two sentences. Although the explanation will incorporate aspects of Stalnaker's theory of conditionals, it will go beyond Stalnaker's analysis of the Oswald example on one crucial point. The difference in focus assignments between the two sentences will not be explained by a difference in appropriateness conditions between indicative and subjunctive mood. Instead, the diverging foci will stem from pragmatic requirements imposed on the presuppositions of indicative and subjunctive antecedents. This analysis will be further confirmed by extending it to similar examples with ascriptions of hopes and wishes, pointing towards a more clear-cut separation of conditionality and the effect of the Oswald example.
\end{abstract}

Keywords Counterfactual $\cdot$ Subjunctive $\cdot$ Focus $\cdot$ Context $\cdot$ Presuppositions

Stefan Rinner

stefan.rinner@uni-hamburg.de

Eugenia Kulakova

eugenia.kulakova@charite.de

1 Charité-Universitätsmedizin Berlin, Klinikum für Psychiatrie und Psychotherapie, Campus Benjamin Franklin, Hindenburgdamm 30, Berlin 12203, Germany

2 University of Hamburg, Überseering 35, Postfach 4, Hamburg 22297, Germany 


\section{Introduction}

A renowned exemplification of a fundamental difference between indicative and subjunctive $^{1}$ conditionals was presented by Adams (1970): ${ }^{2}$

1. If Oswald didn't shoot Kennedy, then someone else did.

2. If Oswald hadn't shot Kennedy, then someone else would have.

Despite (supposedly) identical propositional content, intuitively, (1) is true and (2) is false. This was taken by some philosophers (e.g. Lewis 1973; Gibbard 1981; Jackson 1987; Bennett 2003) to demonstrate a logical difference between indicative and subjunctive conditional operators, and is still regarded as a testing instance for every serious cognitive theory of conditionals (Pearl 2013; Kulakova and Nieuwland 2016; Quelhas et al. 2018; Over and Cruz 2019; Edgington 2020).

Two main lines of argumentation against the interpretation via two different conditional operators have emerged since the original example has been launched. Some authors focused on tense, arguing that the consequents of (1) and (2) were not parallel in their tense structure (Lowe 1979; Barker 1998; Dudman 1985; Edgington 2007; Arregui 2007, 2009; Ippolito 2013). According to this analysis, Lewis' conclusion fails because it rests on the assumption that mood is the only difference between (1) and (2). The main observation here was that the temporal meaning of the construction 'would have [killed]' in the consequent of (2) refers to a prolonged period of time and, therefore, does not match the punctual temporal meaning of 'did [kill]' in (1). This, in turn, results in different meanings of the consequents and, hence, different types of conditionals, one epistemic and the other predictive (Kaufmann 2005).

The second line of argumentation focused on the appropriateness conditions of indicative and subjunctive conditionals. For instance, according to Stalnaker (1968, 1970, 2009, 2019), both (1) and (2) are true if and only if the world most similar to the actual world in which Oswald did not shoot Kennedy is a world in which Kennedy was nevertheless shot. However, while an utterance of (1) is only appropriate if the antecedent is compatible with common ground, for Stalnaker (1975), an utterance of (2) is not subject to any such constraint. Hence, although in the case of (1) the set of (relevant) worlds is narrowed down to the worlds in which Kennedy was shot, in the case of (2), it includes a world in which Kennedy wasn't shot at all. As a consequence, (1) is true, whereas (2) is (possibly) false.

The analysis presented in this paper will take a closer look at the antecedents of the Oswald minimal pair. We will argue that diverging foci in the antecedents of (1) and (2) result in different truth-conditions of the conditionals, explaining the difference in truth values between (1) and (2). Although the explanation will incorporate aspects of Stalnaker's theory of conditionals, it will go beyond Stalnaker's analysis of the Oswald example on one crucial point. The difference in focus assignments between (1) and (2)

\footnotetext{
${ }^{1}$ In this paper, we will use the expressions 'subjunctive conditional' and 'counterfactual conditional' interchangeably. Hence, we do not distinguish between subjunctive conditionals that presuppose the falsity of their antecedents, and subjunctive conditionals that do not.

2 The actual pair is 'If Oswald hadn't shot Kennedy in Dallas, Kennedy would be alive today' and 'If Oswald didn't shoot Kennedy in Dallas, Kennedy is alive today' (Adams 1970). However, following Lewis (1973), it is common to use (1) and (2). The explanation presented in this paper applies mutatis mutandis to Adams' original pair.
} 
will not be explained by a difference in appropriateness conditions between indicative and subjunctive mood. Instead, the diverging foci will stem from pragmatic requirements imposed on the presuppositions of indicative and subjunctive antecedents. This analysis will be further confirmed by extending it to similar examples with ascriptions of hopes and wishes, pointing towards a more clear-cut separation of conditionality and the effect of the Oswald example.

\section{The effect of focus}

For a start, consider a pair of conditionals in which focus ${ }^{3}$ leads to different truth values, in spite of identical wording. The example was introduced by Dretske (1972) and is meant to be evaluated knowing that only marrying puts Clyde in the position to inherit money (see also Rooth 1985, 1999):

3. If Clyde hadn't married $F$ Bertha, he would not have been eligible for inheritance. 4. If Clyde hadn't married Berth $a_{F}$, he would not have been eligible for inheritance. Intuitively, (3) is true, whereas (4) is not. Beaver \& Clark (2008, p. 65-6) provide an explanation for this effect, following Rooth's (1999) discussion of counterfactuals. According to this explanation, the conditional operator has a free variable for an implicit comparison set, i.e. the set of possible worlds under consideration. Beaver \& Clark call this the modal base of the counterfactual. ${ }^{4}$ Starting from Lewis' (1973) and Stalnaker's (1968) analysis of counterfactual conditionals, Beaver \& Clark claim that a counterfactual conditional of the form 'If $A$, then $B$ ' is true at a world $w$ if and only if $B$ is true at the world most similar to $w$, out of the modal base of 'If $A$, then $B$ ', at which $A$ is true. Hence, in order to provide an explanation of the difference in truth values between (3) and (4), the modal bases of (3) and (4) have to be different.

Beaver \& Clark's explanation of why the modal bases of (3) and (4) differ proceeds in two steps. First, they point out that counterfactual conditionals are evaluated with respect to a modal base where the presuppositions of the antecedent are satisfied (see, e.g., Heim 1992, p. 204-5, Ippolito 2003), i.e. the modal base consists only of worlds in which the presuppositions of the antecedent are true. In a second step, they go on to show how a difference in focus assignments between (3) and (4) leads to different presuppositions being made with the respective antecedents. For example, they point out that since the antecedent of (4) is a possible answer to the question 'Who did Clyde marry?', it typically presupposes that Clyde married someone, requiring the modal base of (4) to satisfy this presupposition. ${ }^{5}$ The antecedent of (3), on the other hand, does not make any such presupposition, since it is a possible answer to the question 'What did Clyde do to Bertha?'. Hence, unlike the modal base of (4), the

\footnotetext{
3 A focus is a kind of emphasis in a statement. This emphasis can be achieved in different ways. Sometimes it is due to intonation ('Mary entered the room QUIETLY $_{F}$ '), but it can also be reached by the syntactic structure of the statement ('Quietly ${ }_{F}$ Mary entered the room'). Another possibility is to introduce a copular sentence, for instance a so-called pseudocleft: What Mary likes is pie $F$.

4 The term modal base was introduced by Kratzer (see, e.g., 1977).

5 This is explained with the Current Question Rule, according to which the most recent question of a sequence of (open) questions remains open only if it contains at least one true alternative (Beaver and Clark 2008, p. 38).
} 
modal base of (3) typically includes a world in which Clyde didn't marry at all and, thus, is not eligible for inheritance. ${ }^{6}$

Dretske's example can be duplicated in the indicative mood if we accept the assumption that only marrying puts Clyde in the position to inherit money.

\section{If Clyde didn't marry $F$ Bertha, he was not eligible for inheritance.}

6. If Clyde didn't marry Bertha $a_{F}$, he was not eligible for inheritance.

Again, the antecedent of (5) suggests that Clyde did something else to Bertha than marrying her, whereas the antecedent of (6) assumes that Clyde married someone other than Bertha. Therefore, (5) is (possibly) true, whereas (6) is false. This suggests that in (5) and (6) the same conditional operator is involved as in (3) and (4), referring to an implicit set of possible worlds which, in connection with indicative conditionals, we simply call the comparison set. This is where our account goes beyond Beaver and Clark (2008), Rooth (1985, 1999), and Ogihara (2000, 2013) who discuss focus assignments only in connection with subjunctive conditionals. Starting from Stalnaker's $(1968,1970,2009,2019)$ analysis of indicative conditionals, we claim that an indicative conditional of the form 'If $A$, then $B$ ' is true at a world $w$ if and only if $B$ is true at the world most similar to $w$, out of the comparison set of 'If $A$, then $B$ ', at which $A$ is true. Unlike Stalnaker, we don't require that in indicative mood the comparison set corresponds to the common ground of the conversation at hand, i.e. the set of worlds that have not already been ruled out by the conversational parties. However, in order to explain the difference in truth values between (5) and (6), the comparison set again has to satisfy the presuppositions of the respective antecedents. Hence, just like the modal base of (4), the comparison set of (6) consists only of worlds in which Clyde married someone, whereas the comparison set of (5) includes a world in which Clyde didn't marry at all. ${ }^{7}$

According to this analysis of indicative and subjunctive conditionals, the truthconditions of (3) and (4) correspond to the truth-conditions of (7) and (8), whereas the truth-conditions of (5) and (6) amount to the truth-conditions of (9) and (10).

7. If Clyde had done something else to Bertha than marrying her, he would not have been eligible for inheritance.

8. If Clyde had married someone other than Bertha, he would not have been eligible for inheritance.

9. If Clyde did something else to Bertha than marrying her, he was not eligible for inheritance.

10. If Clyde married someone other than Bertha, he was not eligible for inheritance.

\footnotetext{
6 A similar explanation has been offered by Ogihara (2000, 2013).

7 Note that although the presuppositions of the antecedent of an indicative conditional can be cancelled, cancelling only prevents that the presuppositions project. According to the present account, this does not affect the truth-conditions of the conditional. However, as Over and Cruz (2019) point out, it can affect people's degrees of belief in the respective conditional. Furthermore, cancellability can be seen as a special case of dynamic reasoning as modelled in Bayesian networks (see, e.g., Oaksford and Chater 2013; Pearl 2013; Rips 2010). We would like to thank an anonymous reviewer for pointing this out.
} 
The truth-conditions of the sentences (7)-(10) are then analysed in accordance with a similarity account of indicative and subjunctive conditionals. ${ }^{8}$

These observations are relevant for the Oswald example, since also the antecedents of (1) and (2) allow the introduction of different foci. For the indicative, the possible focus assignments are:

11. If Sswald $_{F}$ did not shoot Kennedy (but Otto did instead), ...

12. If Oswald did not shoot $_{F}$ Kennedy (but stabbed him instead), ...

13. If Oswald did not shoot Kennedy $y_{F}$ (but Kennedy's double instead), ...

14. If Oswald did not shoot Kennedy ${ }_{F}$ (at all), ...

The content of the consequent of (1) helps to eliminate interpretations (12) and (13): 'someone else did' is elliptical for 'someone else did shoot Kennedy', maintaining predicate and object. The interpretations (11) and (14) remain.

Labelling (14) broad and (11) narrow focus, we get a $2 \times 2$ matrix for possible focus assignments for indicative and subjunctive mood, which might be easier to grasp when paraphrased as cleft constructions:

15. Narrow indicative:

If Oswald $F$ did not shoot Kennedy, then someone else did.

If Oswald wasn't the one who shot Kennedy, ...

16. Broad indicative:

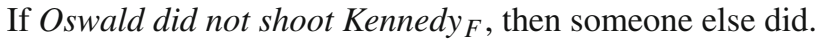

If it did not occur that Oswald shot Kennedy, ...

17. Narrow subjunctive:

If Oswald $_{F}$ had not shot Kennedy, then someone else would have.

If Oswald hadn't been the one who shot Kennedy, ...

18. Broad subjunctive:

If Oswald had not shot Kennedy ${ }_{F}$, then someone else would have.

If it had not occurred that Oswald shot Kennedy, ...

Intuitively, (15) and (17) are true. (16) and (18), on the other hand, both seem to be false. The similarity account presented above can explain this. Since the antecedents of (15) and (17) are possible answers to the question 'Who shot Kennedy?', they presuppose that Kennedy was shot, requiring the comparison set/modal base of (15) and (17) to consist only of worlds in which this presupposition is true. The antecedents of (16) and (18), on the other hand, are possible answers to the general question 'What happened?', making the very unspecific presupposition that something happened. This is why the comparison set/modal base of (16) and (18) includes worlds in which Kennedy wasn't shot at all, explaining why (16) and (18) are (possibly) false.

This suggests that, in the Oswald example, the difference between (1) and (2) can be explained with the fact that focus is narrow in the antecedent of (1) and broad in the antecedent of (2). Why so, if both readings are technically viable in both (1) and (2)? This can be explained by pragmatic requirements imposed on the presuppositions of indicative and subjunctive antecedents, together with the conversational context of the Oswald example.

\footnotetext{
8 In this way, we prevent that (6) and (10) come out as true if their antecedent is false. Even if Clyde didn't marry someone other than Bertha, the world most similar to the actual world in which Clyde married someone other than Bertha is still a world in which Clyde was eligible for inheritance.
} 


\section{The effect of context}

According to Stalnaker (1975, p. 277), uttering an indicative conditional 'If $A$, then $B$ ' is pragmatically only appropriate if the antecedent is compatible with common ground. If the common ground is the set of possible worlds that have not already been ruled out by the conversational parties, this usually means that the common ground includes a world in which $A$ is true. However, once focus is introduced, Stalnaker's appropriateness condition requires a further specification. For example, according to the analysis presented in the last section, the truth-conditions of (6) amount to the truth-conditions of (10). Since (10) is only compatible with common ground if it includes a world in which Clyde married someone other than Bertha, the same is true of (6). Hence, in order for (6) to be appropriate, the common ground not only has to include a world in which its antecedent is true. In addition, this world also has to be part of the comparison set of (6), i.e. it has to satisfy the presuppositions made by the antecedent of (6).

Now, since the antecedent of (15) is a possible answer to the question 'Who shot Kennedy?', it typically presupposes that somebody shot Kennedy. This means that an utterance of (15) is only appropriate if the common ground includes a world in which somebody other than Oswald shot Kennedy. Although it is certain that Kennedy was shot (we saw videos, we saw pictures), it is less certain whether Oswald was the one who shot him (we didn't see videos, we didn't see pictures). This is why the common ground usually includes a world in which somebody other than Oswald shot Kennedy. As a consequence, the narrow scope reading of (1), i.e. (15), is appropriate.

At the same time, the broad scope reading of (1) is pragmatically inappropriate. The antecedent of (16) is a possible answer to the general question 'What happened?', making the very unspecific presupposition that something happened. This is why the truth-conditions of (16) amount to the claim: if the event of Oswald's shooting of Kennedy did not take place, then somebody other than Oswald shot Kennedy. In principle, such a claim is compatible with the common ground of the Oswald example. After all, a world in which somebody other than Oswald shot Kennedy is a world in which Oswald's shooting of Kennedy did not take place. However, an utterance of (16) would also be appropriate if the common ground included a world in which Kennedy wasn't shot at all. Since in the Oswald example this amounts to a loss of information, an utterance of (16) would violate Grice's (1975) Maxim of Quantity, making it pragmatically inappropriate.

Note that an utterance of (15) does not violate the Maxim of Quantity. For example, it has been pointed out that in order for an utterance to be appropriate its presuppositions have to be part of common ground (see, e.g., Karttunen 1974; Stalnaker 1974; Lewis 1979). Hence, since indicative conditionals project the presuppositions of their antecedents (see, e.g., Karttunen 1973), an utterance of (15) requires the common ground to satisfy the presupposition that somebody shot Kennedy. If not already part of common ground, it is implicitly added via presupposition accommodation, a repair mechanism to make sense of otherwise inappropriate utterances. ${ }^{9}$

\footnotetext{
9 The classic references for presupposition accommodation are Karttunen (1974), Stalnaker (1974), and Lewis (1979).
} 
Let's have a look at subjunctive mood, i.e. (2). While indicative antecedents have to be compatible with common ground, subjunctive antecedents signal that no such assumption is being made (Isard 1974; Stalnaker 1975; Lyons 1977; Palmer 1986; Iatridou 2000; Schulz 2007, 2014; Starr 2014). ${ }^{10}$ Still, as Gillies (2017) points out, subjunctive conditionals require their antecedents to be compatible with the counterfactual domain/modal base, so that the set of worlds that are counterfactually relevant in the conversation at hand include a world in which the antecedent is true. ${ }^{11}$ In the Oswald example, this requirement is satisfied by both the antecedent of (17) and the antecedent of (18), since the counterfactual domain of the Oswald example typically includes a world in which somebody other than Oswald shot Kennedy. Nevertheless, speakers tend to read (2) as (18).

Unlike indicative conditionals, subjunctive conditionals do not project the presuppositions of their antecedents (Ippolito 2006). 'If my sister had won the French Open, I would be bragging, too', for instance, does not presuppose that the speaker has a sister. ${ }^{12}$ It only presupposes that the worlds that are counterfactually relevant are such that the speaker has a sister. Similarly, an utterance of (17) only requires the counterfactual domain to satisfy the presupposition that somebody shot Kennedy. Such a counterfactual domain could be relevant in a context where it is assumed that more than one sniper was involved in Kennedy's assassination. However, since usually no such assumption is made, speakers tend to read (2) as (18). On this reading, the counterfactual domain typically includes a world in which Kennedy wasn't shot at all.

\section{Oswald explained}

Starting from the results of the last two sections, we can now explain the difference between (1) and (2). Since, in the Oswald example, the common ground entails that Kennedy was shot, focus has to be narrow in (1). Therefore, the comparison set of (1) includes only worlds in which somebody shot Kennedy, rendering (1) trivially true. The subjunctive (2), on the other hand, has to be read with broad focus. After all, the counterfactual domain of the Oswald example typically includes a world in which Kennedy wasn't shot at all. In other words, the difference in truth-conditions between (1) and (2) amounts to the difference in truth-conditions between (19) and (20), undermining an explanation of the Oswald example via two different conditional operators. $^{13}$

\footnotetext{
10 Some authors advocate the stronger claim that subjunctive antecedents are at least partly incompatible with common ground (see, e.g., Iatridou 2000).

11 This goes beyond Stalnaker's proposal, according to which only indicative conditionals are subject to pragmatic constraints.

12 This does not hold for what Ippolito (2006) calls one-past counterfactuals such as 'If John ran the Boston marathon next year, he would have won'. As Ippolito points out, such an utterance is infelicitous if John died while training for the marathon.

13 A similar rephrasing of the Oswald minimal pair has been proposed by Fogelin (1998), at least for the indicative (1). However, Fogelin does not explain the difference between (1) and (2) with a difference in focus assignments. Instead, Fogelin claims that (1) and (2) are evaluated in different contexts. Fogelin
} 
19. If somebody other than Oswald shot Kennedy, then somebody other than Oswald shot Kennedy.

20. If the event of Oswald's shooting of Kennedy had not taken place, then somebody other than Oswald would have shot Kennedy.

The truth-conditions of indicative and subjunctive conditionals are then analysed in accordance with a similarity account of indicative and subjunctive conditionals. This helps to avoid that the broad reading of the indicative (1) comes out as true if Oswald actually shot Kennedy, ${ }^{14}$ which would otherwise lead to a variant of the Oswald example using only the broad readings of (1) and (2). After all, the broad reading of (2), i.e. (18), seems to be false. ${ }^{15}$

Note that, unlike Stalnaker's explanation of the Oswald example, the present analysis does not explain the difference in truth values between (1) and (2) with a difference in appropriateness conditions between indicative and subjunctive conditionals. After all, none of the possible readings of (1) and (2) are found to be inappropriate by these adequacy constraints. As a result, the analysis presented in this paper does not identify the comparison set of indicative mood with common ground. Instead, the present explanation suggests a uniform analysis of indicative and subjunctive conditionals, according to which the comparison set/modal base implicitly referred to by the conditional operator is consistently restricted by the presuppositions of the respective antecedents. These presuppositions, in turn, are subject to pragmatic constraints imposed by common ground and counterfactual domain.

Besides its uniformity, this analysis has the advantage that the truth-conditions of indicative conditionals are independent of the common ground, avoiding some of the main problems of Stalnaker's account. For example, the sensitivity to common ground of the proposition expressed by an indicative conditional is somewhat unnatural, since we usually distinguish between the content of what is said and the different epistemic attitudes speakers may take to that same content. Hence, if speakers who are agnostic about the conditional 'If Mary isn't home, Peter is' discover that Mary or Peter is home and, thus, start to accept the conditional, we would say that the speakers now believe what they were first agnostic about.

Over (2020) and Over \& Cruz (under review) have argued that (2) can "collapse" to (1) when we find that the antecedent of (2) is true. In this case, our confidence in (2) seems to increase, and it arguably becomes equivalent to (1). According to the explanation presented in this paper, this means that when we find that the antecedent of (2) is true, we tend to read (2) as (17), i.e. with focus on 'Oswald'. The reason for this seems to be that even if speakers find out that Oswald didn't shoot Kennedy, they still believe that Kennedy was shot, making it more likely to evaluate (2) with

presented an analysis in which constant context, together with some rephrasing of the conditionals, cancelled the effect of mood. However, Fogelin did not provide an explanation of what causes the context shift in the first place.

14 If Oswald shot Kennedy, the world most similar to the actual world in which the event of Oswald's shooting of Kennedy did not take place is a world in which Kennedy wasn't shot at all.

15 Note that even according to a similarity account of indicative conditionals the broad reading of (1) is true if somebody other than Oswald shot Kennedy. In this case, the world most similar to the actual world in which the event of Oswald's shooting of Kennedy did not take place is the actual world itself. However, arguably, then (18) is true, too. 
respect to a counterfactual domain that satisfies the presupposition that Kennedy's assassination took place. In other words, if Oswald wasn't responsible for Kennedy's assassination, counterfactual scenarios in which Kennedy wasn't shot at all become less relevant when evaluating (2).

The details of the present analysis of the Oswald example do not necessarily have to be worked out within a similarity account of indicative and subjunctive conditionals. The main thesis of this paper is that the difference in truth values between (1) and (2) has to be explained by a difference in focus assignments, stemming from pragmatic requirements imposed on the presuppositions of indicative and subjunctive antecedents. These diverging foci lead to a difference in truth-conditions between (1) and (2) in line with the difference in truth-conditions between (19) and (20). However, in order to avoid that the broad reading of the indicative (1) comes out as true if Oswald actually shot Kennedy, we have to reject the classic truth-conditions of indicative conditionals, according to which an indicative conditional is true if its antecedent is false. The similarity account of indicative and subjunctive conditionals presented in Sect. 2 is just one way to spell this out.

\section{Further examples}

Using the mechanism described in the last sections, sentence pairs similar to the Oswald example can be constructed. What is required is an antecedent comprising an ambiguity in focus which can be resolved fully (but differently for indicative and subjunctive mood) by relying on the pragmatic requirements imposed on the presuppositions made by the respective antecedents, actual world knowledge, and relevance, combined with a consequent that is sensitive to the emerging context shift. One has already been introduced by Bennett (2003):

21. If Shakespeare did not write Hamlet, then some aristocrat did.

22. If Shakespeare had not written Hamlet, then some aristocrat would have.

Intuitively, indicative (21) is true and subjunctive (22) is false. The existence of a piece of literature called Hamlet is certain, yet it can be doubted that it was Shakespeare who wrote it (see, e.g., Hackett 2009, p. 167). Therefore, in the indicative, focus has to be established on 'Shakespeare'. In the subjunctive, on the other hand, focus has to be broad, since the counterfactual domain typically includes a world in which Hamlet hasn't been written at all. Hence, the difference in truth value between (21) and (22) can again be explained with a difference in focus assignments, resulting in different truth-conditions of the respective conditionals.

Another example is:

23. If the asteroids did not extinguish the dinosaurs, then something else did.

24. If the asteroids had not extinguished the dinosaurs, then something else would have.

Again, intuitively, indicative (23) is true, whereas subjunctive (24) might be false. The dinosaurs are most certainly extinct, yet it is not certain that asteroids caused their unfortunate condition. Therefore, in (23), focus has to be narrow, whereas in (24) 
the more common reading is the one with broad scope, considering a counterfactual domain that leaves open whether the dinosaurs were extinguished at all. ${ }^{16}$

Finally, the present explanation also works for the following variant of the Oswald example, which was first discussed by Adams (1970), where (25) is false and (26) is possibly true.

25. If Oswald didn't shoot Kennedy, then nobody else did.

26. If Oswald hadn't shot Kennedy, then nobody else would have.

Again, this can be explained with the fact that focus is narrow in (25) and broad in (26).

27. If Oswald $F$ didn't shoot Kennedy, then nobody else did.

28. If Oswald hadn't shot Kennedy $y_{F}$, then nobody else would have.

Just like the antecedent of (15), the antecedent of (27) is a possible answer to the question 'Who shot Kennedy?', presupposing that somebody shot Kennedy. The antecedent of (28), on the other hand, makes no such presupposition, which is why its modal base includes worlds in which Kennedy wasn't shot at all.

Arguably, the Oswald example represents a rare case, while in most indicative/subjunctive sentence pairs no intuitive difference in truth-values arises. Prominent cases are conditionals that express causal relations, for instance: ${ }^{17}$

29. If the litmus paper turned red, then the substance was an acid.

30. If the litmus paper had turned red, then the substance would have been an acid.

This is in line with our proposal. First, in the present example, focus does not even affect the truth values of (29) and (30). Although 'The litmus paper turned red ${ }_{F}$ ' is a possible answer to the question 'Which colour did the litmus paper turn to?', it logically entails that the litmus paper turned to a certain colour, rather than presupposing it. Hence, different foci in the antecedents of (29) and (30) would not lead to (29) and (30) being evaluated with respect to different sets of possible worlds.

The case is different if the antecedent is a negation.

31. If the litmus paper didn't turn red, then the substance wasn't an acid.

32. If the litmus paper hadn't turned red, then the substance wouldn't have been an acid.

In (31) and (32), different foci would lead to a difference in truth-conditions, since they would affect the presuppositions made by the respective antecedents. Nevertheless, we have strong intuitions that both (31) and (32) are true. According to the analysis presented in this paper, this can be explained with the fact that speakers tend to read both (31) and (32) with focus on 'red'. After all, what is usually under discussion when testing whether something is an acid is the colour of the litmus paper.

\section{Beyond conditionals}

Since the effect of the original Oswald example primarily stems from an interplay of focus, mood, and conversational context in the interpretation of the antecedent, the

16 This example is actually preferable to the original one, since it does not invoke conspirational notions.

17 We would like to thank an anonymous reviewer for pointing this out. 
question is whether it is replicable outside of conditionals. Iatridou (2000) showed that counterfactual wishes behave most similar to counterfactual conditionals in respect to tense, aspect, and mood. Thus, 'to wish' can be used to express the desire of some state or event in the past that was never realised (Meinunger 2007). Such event is implied to be false and therefore has to be expressed in subjunctive mood and past tense. On the contrary, 'to hope' conveys an ignorant attitude towards the ontological status of the proposition it introduces and is used in combination with indicative mood, similar to the antecedent of an indicative conditional. This allows us to replicate the original Oswald example, as (33) and (34) seem to ascribe different attitudes to the speaker.

33. I hope that Oswald did not shoot Kennedy. \#In that case nobody (else) did.

34. I wish that Oswald had not shot Kennedy.

In that case nobody (else) would have.

We think that the difference between (33) and (34) can again be explained with a difference in focus assignments, stemming from pragmatic requirements imposed on the presuppositions of the embedded sentences. This would further confirm our explanation of the original Oswald example and question a semantic difference between the mental attitude verbs 'to hope' and 'to wish'. For instance, Radford and Hinton (1970) argue that hopes and wishes are closely related through being desires.

Just like in (1) and (2), the following foci can be assigned in (33) and (34):

35. Narrow indicative:

I hope that swald $_{F}$ did not shoot Kennedy.

(I hope that Oswald wasn't the one who shot Kennedy.)

\#In that case nobody (else) did.

36. Broad indicative:

I hope that Oswald did not shoot Kennedy ${ }_{F}$.

(I hope it did not occur that Oswald shot Kennedy.)

In that case nobody (else) did.

37. Narrow subjunctive:

I wish that sswald $_{F}$ had not shot Kennedy.

(I wish that Oswald hadn't been the one who shot Kennedy.)

\#In that case nobody (else) would have.

38. Broad subjunctive:

I wish that Oswald had not shot Kennedy . $_{\text {. }}$

(I wish it had not occurred that Oswald shot Kennedy.)

In that case nobody (else) would have.

Again, similar attitudes are expressed once focus is either broad or narrow in both (33) and (34), suggesting an intuitive reading with a narrow focus in (33) and a broad one in (34).

This difference in focus assignments can be explained with the fact that while a sentence of the form 'I wish that $p$ ' only requires that the presuppositions of the embedded sentence are satisfied by the counterfactual domain, in a sentence of the form 'I hope that $p$ ' the presuppositions of the embedded sentence project and, thus, have to be satisfied by common ground. For example, an utterance of 'I hope my 
sister did win the French Open' presupposes that the speaker has a sister, whereas an utterance of 'I wish my sister had won the French Open' does not. Hence, since it is a reliable part of common knowledge that somebody shot Kennedy, the narrow reading of the indicative (33) is appropriate, whereas the broad reading would again violate Grice's Maxim of Quantity. In the subjunctive (34), on the other hand, focus has to be broad, since the counterfactual domain of the Oswald example typically includes a world in which Kennedy wasn't shot at all. ${ }^{18}$

Starting from the presented analysis of indicative and subjunctive conditionals, we can then explain the difference between (33) and (34) by claiming that both the wish and the hope operator have a free variable for an implicit set of possible worlds which has to satisfy the presuppositions of the embedded sentence. Intuitively, in the case of 'to wish' and 'to hope', the set of possible worlds represents the ascribed wish/hope, consisting of the worlds in which it is true/satisfied. Since, unlike the embedded sentence of (38), the embedded sentence of (35) presupposes that somebody shot Kennedy, the hope ascribed by (35) consists only of worlds in which Kennedy was shot. The wish ascribed by (38), on the other hand, includes worlds in which Kennedy wasn't shot at all, making it appropriate to respond with an utterance of 'In that case nobody (else) would have'.

\section{Conclusion}

The present analysis showed that the antecedents of the original Oswald example are more complex than it has been noticed before: both the indicative and the subjunctive antecedent introduce focus differences, resulting in different truth-conditions of the respective conditionals. This observation implies the inadequacy of a commonly employed interpretation of the antecedents of (1) and (2), according to which they express one and the same proposition. This casts additional doubt that different conditional operators bring about the differing truth values. The truth value effect of the example should instead be regarded as a result of different foci in (1) and (2), stemming from pragmatic requirements imposed on the presuppositions of indicative and subjunctive antecedents. This analysis was further supported by replicating the original Oswald example inside and outside of conditionals. The latter also points toward a more clear-cut separation of conditionality and the effect of the Oswald example.

The present analysis raises several relevant questions for further research. First, it might be interesting to flesh out the implications a focus-sensitive approach has for the validity of inferences involving conditionals, such as modus ponens. For instance, according to the present account of indicative conditionals,

1. If Oswald didn't shoot Kennedy, then somebody other than Oswald shot Kennedy.

2. Oswald didn't shoot Kennedy.

$\therefore$ Somebody other than Oswald shot Kennedy.

\footnotetext{
18 If our common ground were different and entailed the involvement of more than one sniper in Kennedy's assassination, someone emotionally concerned about Oswald could easily wish that Oswald had not shot Kennedy, taking for granted that Kennedy would have been shot either way.
} 
is not valid if in premise 1 focus is on 'Oswald', independent of whether premise 2 and the antecedent of premise 1 have matching foci. The reason for this is that in negations such as 'Oswald didn't shoot Kennedy' focus does not affect truth-conditions, but only gives rise to certain pragmatic implications (Beaver and Clark 2008, p. 49). Accordingly, 'Oswald $F$ didn't shoot Kennedy' only pragmatically implies that somebody shot Kennedy. This is indicated by the fact that the implication is cancellable, i.e. an utterance of 'Oswald $F$ didn't shoot Kennedy' can coherently be followed by an utterance of 'In fact, Kennedy wasn't shot at all'. As a result, 'Oswald $F$ didn't shoot Kennedy' isn't logically equivalent to the antecedent of the narrow scope reading of premise 1, i.e. the antecedent of (19), which is why the above inference is not valid if in premise 1 focus is on 'Oswald'. Nevertheless, rational speakers can infer its conclusion if also premise 2 is read with narrow focus. After all, rational speakers can calculate the pragmatic implication of 'Oswald $F$ didn't shoot Kennedy', i.e. that somebody shot Kennedy. ${ }^{19}$ Something very similar holds for subjunctive conditionals. However, working out the details of both a logic for indicative and subjunctive conditionals and a theory of conditional reasoning, starting from the present explanation of the Oswald example, has to be left for future work.

Funding Open Access funding enabled and organized by Projekt DEAL.

Open Access This article is licensed under a Creative Commons Attribution 4.0 International License, which permits use, sharing, adaptation, distribution and reproduction in any medium or format, as long as you give appropriate credit to the original author(s) and the source, provide a link to the Creative Commons licence, and indicate if changes were made. The images or other third party material in this article are included in the article's Creative Commons licence, unless indicated otherwise in a credit line to the material. If material is not included in the article's Creative Commons licence and your intended use is not permitted by statutory regulation or exceeds the permitted use, you will need to obtain permission directly from the copyright holder. To view a copy of this licence, visit http://creativecommons.org/licenses/by/4. $0 /$.

\section{References}

Adams, E. W. (1970). Subjunctive and indicative conditionals. Foundations of Language, 6, 89-94.

Arregui, A. (2007). When aspect matters: The case of would-conditionals. Natural Language Semantics, 15(3), 221-264.

Arregui, A. (2009). On similarity in counterfactuals. Linguistics and Philosophy, 32(3), 245-278.

19 Note that the above inference is valid if in the antecedent of premise 1 focus is broad. In this case, the antecedent of premise 1 is logically equivalent to 'The event of Oswald's shooting of Kennedy did not take place'. Hence, if premise 2 is true and, thus, Oswald did not shoot Kennedy, the antecedent of the broad reading of premise 1 is satisfied and it logically follows that somebody other than Oswald shot Kennedy. Similar restrictions hold for centering. For example, according to the present account, the following inference is not valid even though premise and conclusion have matching foci:

1. Oswald $F$ didn't shoot Kennedy and nobody other than Oswald shot Kennedy.

$\therefore$ If Oswald $F$ didn't shoot Kennedy, then nobody other than Oswald shot Kennedy.

Since the left conjunct of premise 1 only pragmatically implies that somebody shot Kennedy, premise 1 is true in a world in which Kennedy wasn't shot at all. However, according to the present account, the above conclusion is logically false. If the above conclusion has to be read as 'If somebody other than Oswald shot Kennedy, then nobody other than Oswald shot Kennedy', a world most similar to the actual world in which its antecedent is true is a world in which its consequent is not. 
Barker, S. J. (1998). Predetermination and tense probabilism. Analysis, 58(4), 290-296.

Beaver, D. I., \& Clark, B. Z. (2008). Sense and sensitivity: How focus determines meaning. Oxford: Blackwell.

Bennett, J. (2003). A philosophical guide to conditionals. Oxford: Oxford University Press.

Dretske, F. I. (1972). Contrastive statements. The Philosophical Review, 81(4), 411-437.

Dudman, V. H. (1985). Thinking about the future. Analysis, 45(4), 183.

Edgington, D. (2007). On conditionals. In D. Gabbay \& F. Guenthner (Eds.), Handbook of philosophical logic. Springer.

Edgington, D. (2020). Counterfactual conditionals. In O. Bueno \& S. A. Shalkowski (Eds.), The routledge handbook of modality. Routledge.

Fogelin, R. J. (1998). David Lewis on indicative and counterfactual conditionals. Analysis, 58(4), $286-289$.

Gibbard, A. (1981). Two recent theories of conditionals. In W. Harper, R. Stalnaker, \& G. Pearce (Eds.), Ifs: Conditionals, belief, decision, chance, and time. Dordrecht: Reidel.

Gillies, A. (2017). Conditionals. In B. Hale, C. Wright, \& A. Miller (Eds.), A companion to the philosophy of language. Wiley.

Grice, H. P. (1975). Logic and conversation. In Speech Acts.

Hackett, H. (2009). Shakespeare and Elizabeth. The meaning of two myths. Princeton University Press.

Heim, I. (1992). Presupposition projection and the semantics of attitude verbs. Journal of Semantics, 9(3), $183-221$.

Iatridou, S. (2000). The grammatical ingredients of counterfactuality. Linguistic Inquiry, 31(2), 231-270.

Ippolito, M. (2003). Presuppositions and implicatures in counterfactuals. Natural Language Semantics, 11(2), 145-186.

Ippolito, M. (2006). Semantic composition and presupposition projection in subjunctive conditionals. Linguistics and Philosophy, 29(6), 631-672.

Ippolito, M. (2013). Subjunctive conditionals: A linguistic analysis (Vol. 65). MIT Press.

Isard, S. D. (1974). What would you have done if...? Theoretical Linguistics, 1(1-3), 233-256.

Jackson, F. (1987). Conditionals. Basil Blackwell.

Karttunen, L. (1973). Presuppositions and compound sentences. Linguistic Inquiry, 4(2), 169-193.

Karttunen, L. (1974). Presupposition and linguistic context. Theoretical Linguistics, 1(1-3), 181-194.

Kaufmann, S. (2005). Conditional predictions. Linguistics and Philosophy, 28(2), 181-231.

Kratzer, A. (1977). What 'Must' and 'Can' Must and Can Mean. Linguistics and Philosophy, 1, 337-55.

Kulakova, E., \& Nieuwland, M. S. (2016). Understanding counterfactuality: A review of experimental evidence for the dual meaning of counterfactuals. Language and Linguistics Compass, 10(2), 49-65.

Lewis, D. (1973). Counterfactuals. Harvard University Press.

Lewis, D. (1979). Scorekeeping in a language game. Journal of Philosophical Logic, 8(1), 339-359.

Lowe, E. J. (1979). Indicative and counterfactual conditionals. Analysis, 39(3), 139-141.

Lyons, John. (1977). Semantics. Cambridge University Press.

Meinunger, A. (2007). "In the Mood of Desire and Hope: Remarks on the German Subjunctive, the Verb Second Phenomenon, the Nature of Volitional Predicates, and Speculations on Illocution". In L. De Saussure, J. Moeschler, \& G. Puskas 14 (Eds.), Tense, Mood and Aspect: Theoretical and Descriptive Issues. Brill.

Oaksford, M., \& Chater, N. (2013). Dynamic inference and everyday conditional reasoning in the new paradigm. Thinking \& Reasoning, 19(3), 346-379.

Ogihara, T. (2000). Counterfactuals, Temporal Adverbs, and Association with Focus. In Proceedings of Salt (Vol. 10): 115-131.

Ogihara, T. (2013). Counterfactual conditionals and focus. English Linguistics, 30(2), 509-539.

Over, D. E., \& Cruz, N. (2019). Philosophy and the psychology of conditional reasoning. In A. Aberdein \& M. Inglis (Eds.), Advances in experimental philosophy of logic and mathematics (pp. 225-249). Bloomsbury Academics.

Over, D. E. (2020). The Development of the New Paradigm in the Psychology of Reasoning. In S. Elqayam, I. Douven, J. St. B. T. Evans, \& N. Cruz (Eds.), Logic and Uncertainty in the Human Mind, (pp. 243-263). Abingdon, UK: Routledge.

Over, D.E., \& Cruz, N. (under review). Indicative and Counterfactual Conditionals in the Psychology of Reasoning. In (forthcoming) S. Kaufmann, D. Over, \& G Sharma, Conditionals - Logic, Linguistics, and Psychology. Palgrave Macmillan.

Palmer, F. R. (1986). Mood and Modality. Cambridge: Cambridge University Press.

Pearl, J. (2013). Structural Counterfactuals: A Brief Introduction. Cognitive Science, 37(6), 977-985. 
Quelhas, A. C., Rasga, C., \& Johnson-Laird, P. N. (2018). The Relation between Factual and Counterfactual Conditionals. Cognitive Science, 42(7), 2205-2228.

Radford, \& Hinton. (1970). Hoping and Wishing. Proceedings of the Aristotelian Society, Supplementary Volumes, 44, 51-88.

Rips, L. J. (2010). Two Causal Theories of Counterfactual Conditionals. Cognitive Science, 34, 175-221.

Rooth, M. (1985). Association with Focus. Graduate Linguistics Student Association: University of Massachusetts at Amherst.

Rooth, M. (1999). Association with Focus or Association with Presupposition? In P. Bosch \& R. van der Sandt (Eds.), Focus: Linguistic, Cognitive and Computational Perspectives (pp. 232-44). Cambridge: Cambridge University Press.

Schulz, K. (2007). Minimal Models in Semantics and Pragmatics: Free Choice, Exhaustivity, and Conditionals. PhD Thesis. Amsterdam: University of Amsterdam: Institute for Logic, Language and Computation.

Schulz, K. (2014). Fake Tense in Conditional Sentences: A Modal Approach. Natural Language Semantics, 22(2), 117-144.

Stalnaker, R. (1968). A Theory of Conditionals. In N. Rescher (Ed.), Studies in Logical Theory. Oxford: Blackwell.

Stalnaker, R. (1970). Probability and Conditionals. Philosophy of Science, 37(1), 64-80.

Stalnaker, R. (1974). Pragmatic Presuppositions. In Context and Content, (pp. 47-62). Oxford: Oxford University Press.

Stalnaker, R. (1975). Indicative Conditionals. Philosophia, 5(3), 269-286.

Stalnaker, R. (2009). Conditional Propositions and Conditional Assertions. In Andy Egan \& B. Weatherson (Eds.), Epistemic Modality. Oxford: Oxford University Press.

Stalnaker, R. (2019). Knowledge and Conditionals: Essays on the Structure of Inquiry. Oxford: Oxford University Press.

Starr, W. B. (2014). A Uniform Theory of Conditionals. Journal of Philosophical Logic, 43(6), 1019-1064.

Publisher's Note Springer Nature remains neutral with regard to jurisdictional claims in published maps and institutional affiliations. 